\title{
Moralistic gods, supernatural punishment and the expansion of human sociality
}

Benjamin Grant Purzycki ${ }^{1}$, Coren Apicella ${ }^{2}$, Quentin D. Atkinson ${ }^{3,4}$, Emma Cohen ${ }^{5,6}$, Rita Anne McNamara ${ }^{7}$, Aiyana K. Willard ${ }^{8}$, Dimitris Xygalatas $9,10,11$, Ara Norenzayan ${ }^{7}$ \& Joseph Henrich $7,12,13$

Since the origins of agriculture, the scale of human cooperation and societal complexity has dramatically expanded ${ }^{1,2}$. This fact challenges standard evolutionary explanations of prosociality because well-studied mechanisms of cooperation based on genetic relatedness, reciprocity and partner choice falter as people increasingly engage in fleeting transactions with genetically unrelated strangers in large anonymous groups. To explain this rapid expansion of prosociality, researchers have proposed several mechanisms ${ }^{3,4}$. Here we focus on one key hypothesis: cognitive representations of gods as increasingly knowledgeable and punitive, and who sanction violators of interpersonal social norms, foster and sustain the expansion of cooperation, trust and fairness towards co-religionist strangers ${ }^{5-8}$. We tested this hypothesis using extensive ethnographic interviews and two behavioural games designed to measure impartial rule-following among people $(n=591$, observations $=35,400)$ from eight diverse communities from around the world: (1) inland Tanna, Vanuatu; (2) coastal Tanna, Vanuatu; (3) Yasawa, Fiji; (4) Lovu, Fiji; (5) Pesqueiro, Brazil; (6) Pointe aux Piments, Mauritius; (7) the Tyva Republic (Siberia), Russia; and (8) Hadzaland, Tanzania. Participants reported adherence to a wide array of world religious traditions including Christianity, Hinduism and Buddhism, as well as notably diverse local traditions, including animism and ancestor worship. Holding a range of relevant variables constant, the higher participants rated their moralistic gods as punitive and knowledgeable about human thoughts and actions, the more coins they allocated to geographically distant co-religionist strangers relative to both themselves and local co-religionists. Our results support the hypothesis that beliefs in moralistic, punitive and knowing gods increase impartial behaviour towards distant co-religionists, and therefore can contribute to the expansion of prosociality.

Among the other factors ${ }^{2-4,7}$ that influence the emergence of human ultrasociality and complex societies, the diffusion of explicit beliefs in increasingly moralistic, punitive and knowledgeable gods may have played a crucial role $e^{6,7}$. People may trust in, cooperate with and interact fairly within wider social circles, partly because they believe that knowing gods will punish them if they do not. Additionally, through increased frequency and consistency in belief and behaviour sets, commitments to the same gods coordinate people's expectations about social interactions ${ }^{5-9}$. Moreover, the social radius within which people are willing to engage in behaviours that benefit others at a cost to themselves may enlarge as gods' powers to monitor and punish increase $\mathrm{e}^{10}$. To account for the emergence of these patterns, some evolutionary approaches to religion have theorized that cultural evolution may have harnessed and exploited aspects of our evolved psychology, such as mentalizing abilities, dualistic tendencies and sensitivity to norm compliance, to gradually assemble configurations of supernatural beliefs that promote greater cooperation and trust within expanding groups, leading to greater success in intergroup competition. Of course, given that cultural evolution can produce self-reinforcing stable patterns of beliefs and practices, these supernatural agent concepts may also have been individually favoured within groups due to mechanisms related to signalling, reputation and punishment ${ }^{5-9,11,12}$. Over time, these deities spread culturally and came to dominate the modern world religions like Christianity, Islam and Hinduism. Such traditions eventually came to account for a large proportion of the world's population ${ }^{6,7,13,14}$ (see Supplementary Information section S1). Here we directly test one specific hypothesis: conceptions of moralistic and punitive gods that know people's thoughts and behaviours promote impartiality towards distant co-religionists, and as a result contribute to the expansion of sociality.

At the societal level, several lines of converging evidence are consistent with this hypothesis. For example, after controlling for key correlates, analyses of cross-cultural data sets show that larger and more politically complex societies tend to have more supernatural punishment and moralistic deities ${ }^{5,15}$, and historical analyses in one geographic region show that precursors to supernatural punishment beliefs precede social complexity ${ }^{16}$. However, this data derives from qualitative ethnographies of entire societies; a more focused, direct and systematic cross-cultural assessment of what individuals think their gods care about, and whether or not people explicitly or implicitly view their gods as concerned with norms of interpersonal social behaviour (termed here as 'morality ${ }^{17,18}$; see Supplementary Information section S4.2) has only recently begun ${ }^{18-20}$. Analyses of cross-national databases (for example, the World Values Survey) reveal positive relationships between beliefs in hell, beliefs in gods' power to punish, and various self-reported prosocial behaviours ${ }^{21,22}$. Although valuable, these lines of research primarily rely on survey questions not specifically designed to address the research question we are interested in. Moreover, they rely on samples drawn broadly from nation states, thus excluding smallscale societies that are crucial for assessing questions about the expansion of prosociality.

At the individual level, two types of behavioural studies are also consistent with this hypothesis, but each has crucial limitations. First, laboratory experiments show that exposure to religious reminders increases generosity and decreases cheating among religious believers ${ }^{23-25}$. However, as is the case for most psychological experiments, the vast majority of these studies rely on Western, Christianmajority samples, limiting their generalizability ${ }^{26}$. Second, in one

${ }^{1}$ Centre for Human Evolution, Cognition, and Culture, University of British Columbia, 1871 West Mall, Vancouver, British Columbia V6T 1Z2, Canada. ${ }^{2}$ Department of Psychology, University of Pennsylvania, Solomon Laboratories, 3720 Walnut Street, Philadelphia, Pennsylvania 19104-6241, USA. ${ }^{3}$ Department of Psychology, University of Auckland, Human Sciences Building,

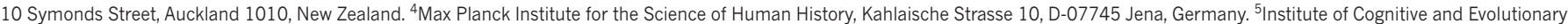
Anthropology, University of Oxford, 64 Banbury Road, Oxford OX2 6PN, UK. ${ }^{6}$ Wadham College, University of Oxford, Parks Road, Oxford, OX1 3PN, UK. ${ }^{7}$ Department of Psychology, University of

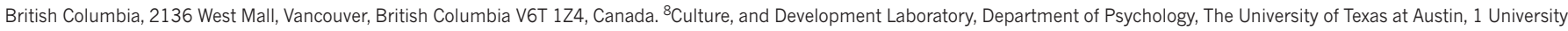
Station \#A8000, Austin, Texas 78712-0187, USA. ${ }^{9}$ Department of Anthropology, University of Connecticut, 354 Mansfield Road, Unit 1176, Storrs, Connecticut 06029, USA. ${ }^{10}$ Interacting Minds

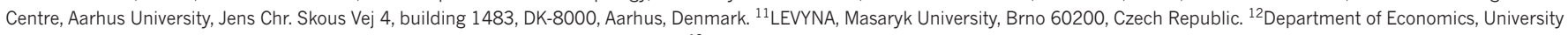

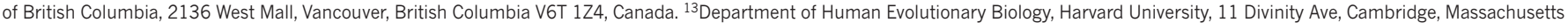
02138, USA. 
Table 1 | Site descriptive statistics

\begin{tabular}{|c|c|c|c|c|c|c|c|c|}
\hline Site & Researcher & Economy & Moralistic god & Local god or spirit & $n$ & Females & Age & Material insecurity \\
\hline Coastal Tanna§ & Atkinson & Horticulture & Christian god & Garden spirit (Tupunus) & 44 & 23 & $35.02(14.13)$ & $0.22(0.36)$ \\
\hline Hadza & Apicella & Hunting & Celestial figure (Haine) $)^{\#}$ & Sun $(I s h o k o)^{\#}$ & 68 & 31 & $39.82(12.08)$ & $0.82^{\ddagger}(0.36)$ \\
\hline Inland Tanna§ & Atkinson & Horticulture & Kalpapan (traditional) & Garden spirit (Tupunus) & 76 & 38 & $37.00(16.17)$ & $0.26(0.38)$ \\
\hline Lovu & Willard & Wage labour & Hindu Bhagwan & None available & 76 & 52 & $44.56(16.94)$ & $0.83(0.33)$ \\
\hline Mauritius & Xygalatas & Wage labour and farming & Hindu Shiva & Spirit/soul/ghost (Nam) & 94 & 27 & $36.56(15.05)$ & $0.39(0.35)$ \\
\hline Pesqueiro & Cohen & Wage labour & Christian god & Virgin Mary & 77 & 40 & $34.12(13.08)$ & $0.86(0.24)$ \\
\hline Tyva Republic & Purzycki & Wage labour and herding & Buddha Burgan & Spirit-masters (Cher eezi) & 81 & 58 & $33.53(12.52)$ & $0.47(0.28)$ \\
\hline \multirow[t]{2}{*}{ Yasawa } & McNamara & Fishing and farming & Christian god & Ancestor spirits (Kalou-vu) & 75 & 41 & $38.04(15.91)$ & $0.50(0.40)$ \\
\hline & & & & Grand mean & 73.88 & - & 37.34 & 0.55 \\
\hline
\end{tabular}

Means indicated (standard deviations in parentheses). See Extended Data Fig. 1 for a map of field sites.

$\S$ One individual was removed from the local co-religionist game due to coin visibility.

\#These two gods closely overlap in conception.

$\ddagger$ Answer options were "yes", "no" or "I don’t know".

field study ${ }^{27}$ across 15 diverse societies of foragers, pastoralists and horticulturalists, adherence to Christianity or Islam predicted greater fairness in economic games relative to adherence to local/traditional religions. This study, however, lacked precise measures for our theoretically important components of beliefs about gods' minds-punishment, knowledge and moralism. Moreover, these studies did not consider the religious affiliation of the anonymous recipients of players' monetary decisions. It is therefore unclear whether these findings explain the expansion of prosociality specifically towards geographically distant co-religionists.

Addressing these limitations, we combined two behavioural experiments with detailed ethnographic interviews to assess whether participants who report that their moralistic gods are punishing and more knowledgeable about human thought and behaviour are more likely to impartially allocate money to anonymous, geographically distant co-religionists over both themselves and their local community ${ }^{6,7}$. In five of the sites, we also tested whether religious priming associated with moralistic gods had effects on gameplay, but these had no overall effect (see Supplementary Information sections S2.2.2 and S6.2.

We tested these predictions with a sample of 591 participants $(310$ females; observations = 35,400; Table 1 and Extended Data Fig. 1) from eight diverse communities, including hunter-gatherers, horticulturalists, herders and farmers, as well as fully market-integrated populations engaged in wage labour or operating small businesses. The participants adhere to a variety of world religious traditions including Christianity, Hinduism and Buddhism, and report beliefs in an immense range of local supernatural agents, including spirit-masters, saints, ancestors, animistic beings, anthropomorphic celestial deities, garden spirits, and ghosts (Supplementary Information section S3).

To measure favouritism towards oneself and local community under maximally anonymous conditions, we modified the random allocation game $e^{9,28,29}$. In this game (Fig. 1), participants play in private with 30 coins, two cups and a fair die with three sides of one colour and three sides of another colour. In the experiment, the participant's job is to allocate each coin to one of the two cups. First, they mentally choose one of the cups and then roll the die. If one coloured side comes up, players are instructed to put the coin into the cup they mentally

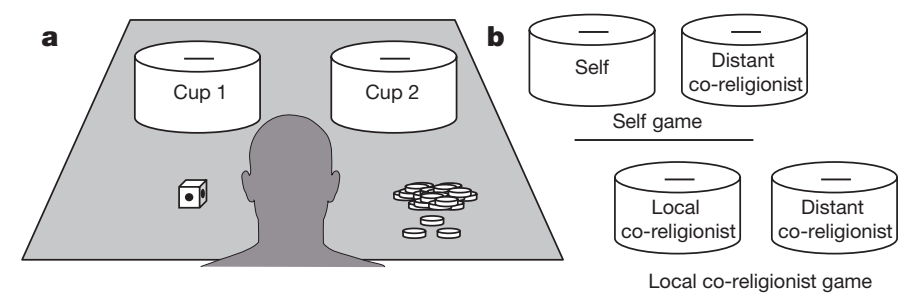

Figure 1 | The random allocation game. a, b, Generic game setup (a) and variants used in present work (b). chose. If the die comes up the other colour, people are instructed to put the coin into the opposite cup from the one they chose. Of course, as cup selection occurs only mentally, participants can overrule the die in favour of one of the cups without anyone else observing their decision. If people play by the rules and thereby allocate the coins impartially, the mean number of coins in each cup should be 15 , and the distribution around this average will be binomial. This allows us to test for systematic deviations from this distribution (Supplementary Information section S2.2).

Participants played two counterbalanced games for a total of 60 coin allocations per person (Fig. 1). In one game, the local co-religionist game, participants chose between a cup assigned to an unspecified anonymous co-religionist from their local community and a cup assigned to an anonymous co-religionist living in a geographically distant community that does not regularly interact with the player's community. In the other game, the self game, participants chose between a cup for themselves and a cup for another anonymous distant co-religionist. In order to control for any effects of ethnicity ${ }^{30}$ and nationality, both local and distant co-religionists were of the same ethnic group and nationality as the participant.

Participants understood that money put into the cups would be given to the people they represented, including themselves, and we actually distributed allocations to participants and randomly selected people described by the cups (that is, there was no deception). After gameplay, we asked each participant a battery of questions, including a series of counterbalanced questions about two locally relevant deities (Supplementary Information section S2).

To assess the gods' relative moral concern, we conducted preliminary ethnographic interviews in each site to identify the most moralistic deities (that is, 'moralistic gods'), as well as locally salient, relatively less moralistic, 'local gods' or spirits. We verified the degree to which gods care about morality with a free-list task asking about gods' concerns ${ }^{19}$ and scales created to measure how important participants claim punishing theft, murder and deceit are to these supernatural beings. We measured gods' punishment and knowledge, using the mean of two, two-item, easy-to-understand scales with dichotomous responses. The target gods associated with games were rated significantly more moralistic, knowledgeable and punitive than local gods (see Extended Data Figs 2 and 3; Supplementary Information section S4). We also aggregated gods' punishment and knowledge scores by averaging all four dichotomous responses, labelled 'punishment-knowledge combined' in Table 2. These measures are our key theoretical predictors for game allocations.

Figure 2 displays the effect of punishment for moralizing gods, without any controls, and reveals the impact of "I don't know" answers which were otherwise excluded from our analyses below. When people report not knowing if a god punishes, they put considerably fewer coins in the cups for distant co-religionists in both games (local coreligionist game: $M=12.97$, s.d. $=4.33$; self game: $M=12.50$, s.d. $=4.15$ ) than those who consistently report that their god punishes (local co-religionist game: $M=14.58$, s.d. $=3.24$; self game: $M=14.53$, 
Table 2 | Log odds ratios for predicting allocations to distant co-religionists with $95 \%$ confidence intervals from our main binomial logistic regression models

\begin{tabular}{|c|c|c|c|c|}
\hline Variable & $\begin{array}{l}\text { Local } \\
\text { co-religionist } \\
\text { game }\end{array}$ & $\begin{array}{l}\text { Local } \\
\text { co-religionist } \\
\text { game }\end{array}$ & Self game & Self game \\
\hline $\begin{array}{l}\text { Moralistic gods' } \\
\text { punishment }\end{array}$ & $\begin{array}{c}1.15 \\
(1.03,1.27)^{*}\end{array}$ & - & $\begin{array}{c}1.11 \\
(1.00,1.23) \dagger\end{array}$ & - \\
\hline $\begin{array}{l}\text { Moralistic gods' } \\
\text { knowledge }\end{array}$ & $\begin{array}{c}1.17 \\
(1.00,1.36)^{*}\end{array}$ & - & $\begin{array}{c}1.22 \\
(1.05,1.42) *\end{array}$ & - \\
\hline $\begin{array}{l}\text { Punishment- } \\
\text { knowledge } \\
\text { combined }\end{array}$ & - & $\begin{array}{c}1.20 \\
(1.04,1.37)^{*}\end{array}$ & - & $\begin{array}{c}1.23 \\
(1.07,1.41)^{* *}\end{array}$ \\
\hline $\begin{array}{l}\text { Material } \\
\text { insecurity }\end{array}$ & $\begin{array}{c}1.02 \\
(0.92,1.12)\end{array}$ & $\begin{array}{c}1.01 \\
(0.92,1.11)\end{array}$ & $\begin{array}{c}0.98 \\
(0.89,1.08)\end{array}$ & $\begin{array}{c}0.96 \\
(0.88,1.06)\end{array}$ \\
\hline $\begin{array}{l}\text { Number of } \\
\text { children }\end{array}$ & $\begin{array}{c}0.98 \\
(0.96,1.00) \dagger\end{array}$ & $\begin{array}{c}0.99 \\
(0.97,1.01)\end{array}$ & $\begin{array}{c}0.98 \\
(0.96,1.00) *\end{array}$ & $\begin{array}{c}0.98 \\
(0.96,1.00) *\end{array}$ \\
\hline$n$ & 503 & 519 & 504 & 520 \\
\hline Observations & 15,090 & 15,570 & 15,120 & 15,600 \\
\hline
\end{tabular}

All models in this table include field site and additional control variables as fixed effects. For all punishment-knowledge aggregate models, see Extended Data Table 1 (highlights from models 1 and 4 presented here) and Supplementary Table S9. See Supplementary Tables S5 and S6 for al other models (highlights from models $1 \mathrm{FE}$ presented here). Odds ratios $>1$ indicate greater odds in allocating a coin to the distant co-religionist. $* * P \leq 0.01, * P \leq 0.05, \uparrow P \leq 0.10$

s.d. = 3.31). One way to estimate the magnitude of these effects is to calculate the quotient of deviations from the ideal impartial allocation of 15. Compared to those who don't know, claiming the moralizing god punishes increases allocations towards distant co-religionists in the self game by a factor of 4.8 and in the local co-religionist game by a factor of 5.3. Extended Data Figs 4 and 5 detail the overall allocation distributions for both games.

We explored this relationship in more detail by regressing the number of coins allocated to the distant co-religionist cup on a host of variables for each game in a large set of binomial regressions (Extended Data Table 1 and Supplementary Information section S6). Table 2 shows a subset of the key predictors for the models with the largest set of control variables, including a number of economic and demographic variables such as education, material insecurity, number of children and field site fixed effects. Using sites as fixed effects allows us to remove the variation between our sites, so the results in Table 2 only capture the differences among individuals within sites. Based on previous work $\mathrm{k}^{9,29}$, we suspected that material insecurity and number of children would increase self and local favouritism, and therefore

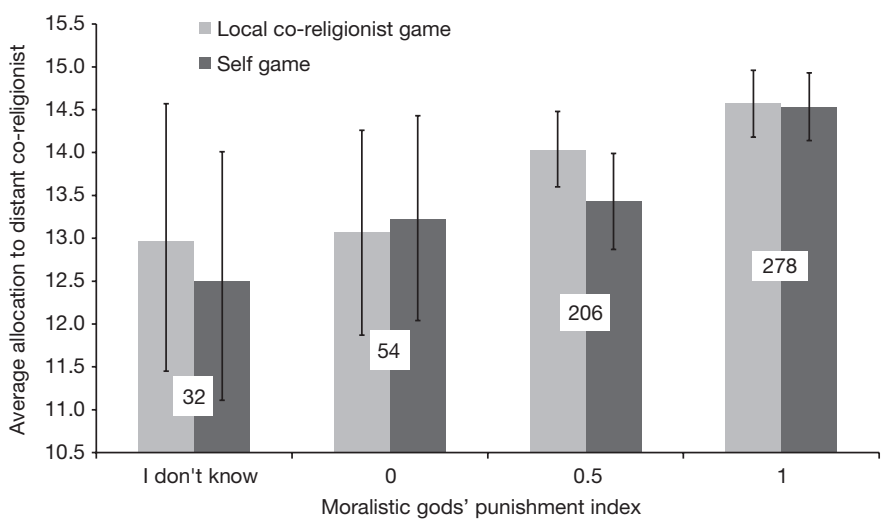

Figure 2 | Allocations to distant co-religionists increase as a function of moralistic gods' punishment. Punishment indices are mean values of a two-item scale (see Supplementary Information section S2.3.2). Error bars represent bootstrapped (1,000 replications) $95 \%$ confidence intervals of the mean. Histogram labels are sample sizes per category. Note that among the 32 individuals who responded "I don't know" to the questions pertaining to moralistic gods' punishment, 17 were Hadza and 15 were inland Tannese.

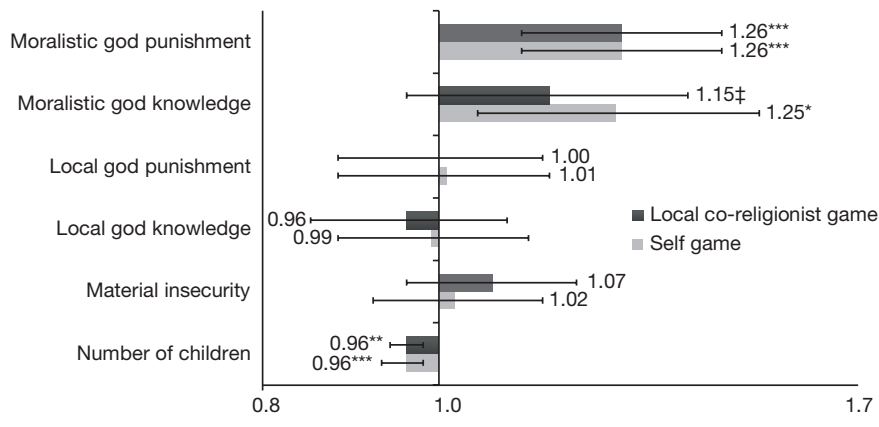

Log odds of coin going to distant co-religionist

Figure 3 | Log odds ratios with $95 \%$ confidence interval plots of the influence of key variables on the odds that a coin goes into the cup for the distant co-religionist. Odds ratios $>1$ indicate an increase and odds ratios $<1$ indicate a decrease in the odds of allocating a coin to the distant co-religionist $(* * * P \leq 0.001, * * P \leq 0.01 ; * P \leq 0.05 ; \ddagger P \leq 0.15)$. The $x$ axis is on a logarithmic scale. Both models include other controls $(n=390)$. Local co-religionist and self results include sites as fixed effects. Note that Indo-Fijians are not included in these models due to the lack of data for local gods. See Supplementary Tables S5 and S6 for full models (models $2 \mathrm{FE}$ are presented here).

we include both in our model (Supplementary Information section S2.3.1). To affirm the robustness of these analyses, we estimated many alternative models, formulated mixed models, and used both alternative standard error estimates and different approaches to modelling the error (Supplementary Information section S5.4). Across a wide range of specifications and models including a host of variables (for example, divine rewards, emotional closeness to distant co-religionists, among others), both moralistic gods' punishment and knowledge, as well as our aggregate punishment-knowledge variable, are reliably associated with less bias against distant co-religionists (Supplementary Tables S5-S9).

We checked whether the effects of moralistic gods' punishment and knowledge were indeed specific to powerful, moralizing gods. We added local gods' punishment and knowledge to the models presented in Table 2. Figure 3 shows the odds ratios and confidence intervals for these coefficients. Although neither the punishing powers nor knowledge of these local deities had any association with the allocations, the odds ratios for our key predictors pertaining to moralistic gods actually increased. These overall findings are correlational and should be interpreted with caution and in combination with other evidence, also considering that religious priming did not reveal consistent effects. However, these patterns reduce concerns that omitted third variables might account for the correlations we observe. A third variable, in addition to correlating with allocations, would have to correlate only with the punishing and knowing character of moralistic and knowledgeable gods, but not with those same attributes in local gods or with the tendency of either type of deity to reward people.

These results build on previous findings and have important implications for understanding the evolution of the wide-ranging cooperation found in large-scale societies. Moreover, when people are more inclined to behave impartially towards others, they are more likely to share beliefs and behaviours that foster the development of larger-scale cooperative institutions, trade, markets and alliances with strangers. This helps to partly explain two phenomena: the evolution of large and complex human societies and the religious features of societies with greater social complexity that are heavily populated by such gods $s^{6,7}$. In addition to some forms of religious rituals and non-religious norms and institutions, such as courts, markets and police, the present results point to the role that commitment to knowledgeable, moralistic and punitive gods plays in solidifying the social bonds that create broader imagined communities ${ }^{11,12,31}$. 
Online Content Methods, along with any additional Extended Data display items and Source Data, are available in the online version of the paper; references unique to these sections appear only in the online paper.

Received 10 June 2015; accepted 7 January 2016.

Published online 10 February 2016.

1. Richerson, P. J. \& Boyd, R. Complex societies: the evolutionary origins of a crude superorganism. Hum. Nat. 10, 253-289 (1999).

2. Turchin, P. in Cultural Evolution: Society, Technology, Language, and Religion (eds Richerson, P. J. \& Christiansen, M. H.) 61-73 (MIT Press, 2013).

3. Fehr, E., Fischbacher, U. \& Gächter, S. Strong reciprocity, human cooperation, and the enforcement of social norms. Hum. Nat. 13, 1-25 (2002).

4. Turchin, P., Currie, T. E., Turner, E. A. L. \& Gavrilets, S. War, space, and the evolution of Old World complex societies. Proc. Natl Acad. Sci. USA 110, 16384-16389 (2013).

5. Johnson, D. D. P. God's punishment and public goods. Hum. Nat. 16, 410-446 (2005).

6. Norenzayan, A. Big Gods: How Religion Transformed Cooperation and Conflict (Princeton Univ. Press, 2013).

7. Norenzayan, A. et al. The cultural evolution of prosocial religions. Behav. Brain Sci. http://dx.doi.org/10.1017/S0140525X14001356 (2015).

8. Schloss, J. P. \& Murray, M. J. Evolutionary accounts of belief in supernatural punishment: a critical review. Relig. Brain Behav. 1, 46-99 (2011).

9. McNamara, R. A., Norenzayan, A. \& Henrich, J. Supernatural punishment, in-group biases, and material insecurity: experiments and ethnography from Yasawa, Fiji. Relig. Brain Behav. 6, 34-55 (2016).

10. Rossano, M. J. Supernaturalizing social life. Hum. Nat. 18, 272-294 (2007).

11. Sosis, R. \& Bressler, E. R. Cooperation and commune longevity: a test of the costly signaling theory of religion. Cross-Cultural Res. 37, 211-239 (2003).

12. Sosis, R. \& Ruffle, B. J. Religious ritual and cooperation: testing for a relationship on Israeli religious and secular kibbutzim. Curr. Anthropol. 44, 713-722 (2003)

13. Atran, S. \& Henrich, J. The evolution of religion: how cognitive by-products, adaptive learning heuristics, ritual displays, and group competition generate deep commitments to prosocial religions. Biol. Theory 5, 18-30 (2010).

14. Pew Research Centres The Future of World Religions: Population Growth Projections 2010-2050. http://www.pewforum.org/files/2015/03/ PF_15.04.02_ProjectionsFullReport.pdf (2015).

15. Botero, C. A. et al. The ecology of religious beliefs. Proc. Natl Acad. Sci. USA 111, 16784-16789 (2014)

16. Watts, J. et al. Broad supernatural punishment but not moralizing high gods precede the evolution of political complexity in Austronesia. Proc. $R$. Soc. Lond. B 282, 20142556 (2015)

17. Haidt, J. \& Kesebir, S. in Handbook of Social Psychology 797-832 (Wiley, 2010)

18. Purzycki, B. G. The minds of gods: a comparative study of supernatural agency. Cognition 129, 163-179 (2013)

19. Purzycki, B. G. Tyvan cher eezi and the socioecological constraints of supernatural agents' minds. Relig. Brain Behav. 1, 31-45 (2011).

20. Purzycki, B. G. et al. What does God know? Supernatural agents' access to socially strategic and non-strategic information. Cogn. Sci. 36, 846-869 (2012).
21. Atkinson, Q. D. \& Bourrat, P. Beliefs about God, the afterlife and morality support the role of supernatural policing in human cooperation. Evol. Hum. Behav. 32, 41-49 (2011).

22. Shariff, A. F. \& Rhemtulla, M. Divergent effects of beliefs in heaven and hell on national crime rates. PLOS ONE 7, e39048 (2012).

23. Bering, J. M., McLeod, K. \& Shackelford, T. K. Reasoning about dead agents reveals possible adaptive trends. Hum. Nat. 16, 360-381 (2005)

24. Piazza, J., Bering, J. M. \& Ingram, G. 'Princess Alice is watching you': children's belief in an invisible person inhibits cheating. J. Exp. Child Psychol. 109, 311-320 (2011)

25. Shariff, A. F., Willard, A. K., Andersen, T. \& Norenzayan, A. Religious priming: a meta-analysis with a focus on prosociality. Personal. Soc. Psychol. Rev. 20, 27-48 (2016).

26. Henrich, J., Heine, S. J. \& Norenzayan, A. The weirdest people in the world? Behav. Brain Sci. 33, 61-83 (2010).

27. Henrich, J. et al. Markets, religion, community size, and the evolution of fairness and punishment. Science 327, 1480-1484 (2010).

28. Cohn, A., Fehr, E. \& Maréchal, M. A. Business culture and dishonesty in the banking industry. Nature 516, 86-89 (2014).

29. Hruschka, D. et al. Impartial institutions, pathogen stress and the expanding social network. Hum. Nat. 25, 567-579 (2014).

30. Chuah, S.-H., Hoffmann, R., Ramasamy, B. \& Tan, J. H. W. Religion, ethnicity and cooperation: an experimental study. J. Econ. Psychol. 45, 33-43 (2014).

31. Xygalatas, D. et al. Extreme rituals promote prosociality. Psychol. Sci. 24, 1602-1605 (2013)

Supplementary Information is available in the online version of the paper.

Acknowledgements We thank everyone who participated in the study and our local assistants without whom this project would not have been possible. We acknowledge funding from a research grant, "The Emergence of Prosocia Religions" from the John Templeton Foundation, and the Cultural Evolution of Religion Research Consortium (CERC), funded by a generous partnership grant (895-2011-1009) from the Social Sciences and Humanities Research Council of Canada. Q.D.A. is grateful for the support provided by a Rutherford Discovery Fellowship, E.C. thanks the British Academy for Fellowship support, J.H. thanks the Canadian Institute for Advanced Research for support, A.N. thanks the James McKeen Cattell Foundation for sabbatical support, and B.G.P. thanks L. Loveridge and J. McCutcheon. We thank A. Baimel, A. Barnett, J. Bulbulia, N. Chan, M. Collard, T. Lai, J. Lanman, B. Milner, M. Muthukrishna, C. Placek, E. Slingerland, R. Sosis, H. Whitehouse and C. Xu.

Author Contributions J.H., A.N. and B.G.P. conceived the study, prepared protocols, managed project communication and initiated manuscript preparation. C.A., Q.D.A., E.C., R.A.M., A.K.W., B.G.P. and D.X. collected data. B.G.P. conducted all analyses, made all graphs, Tables and illustrations. All authors participated in developing and refining protocols, experimental design and in manuscript preparation.

Author Information Reprints and permissions information is available at www.nature.com/reprints. The authors declare no competing financial interests. Readers are welcome to comment on the online version of the paper. Correspondence and requests for materials should be addressed to B.G.P. (bgpurzycki@alumni.ubc.ca) or J.H. (henrich@psych.ubc.ca). 


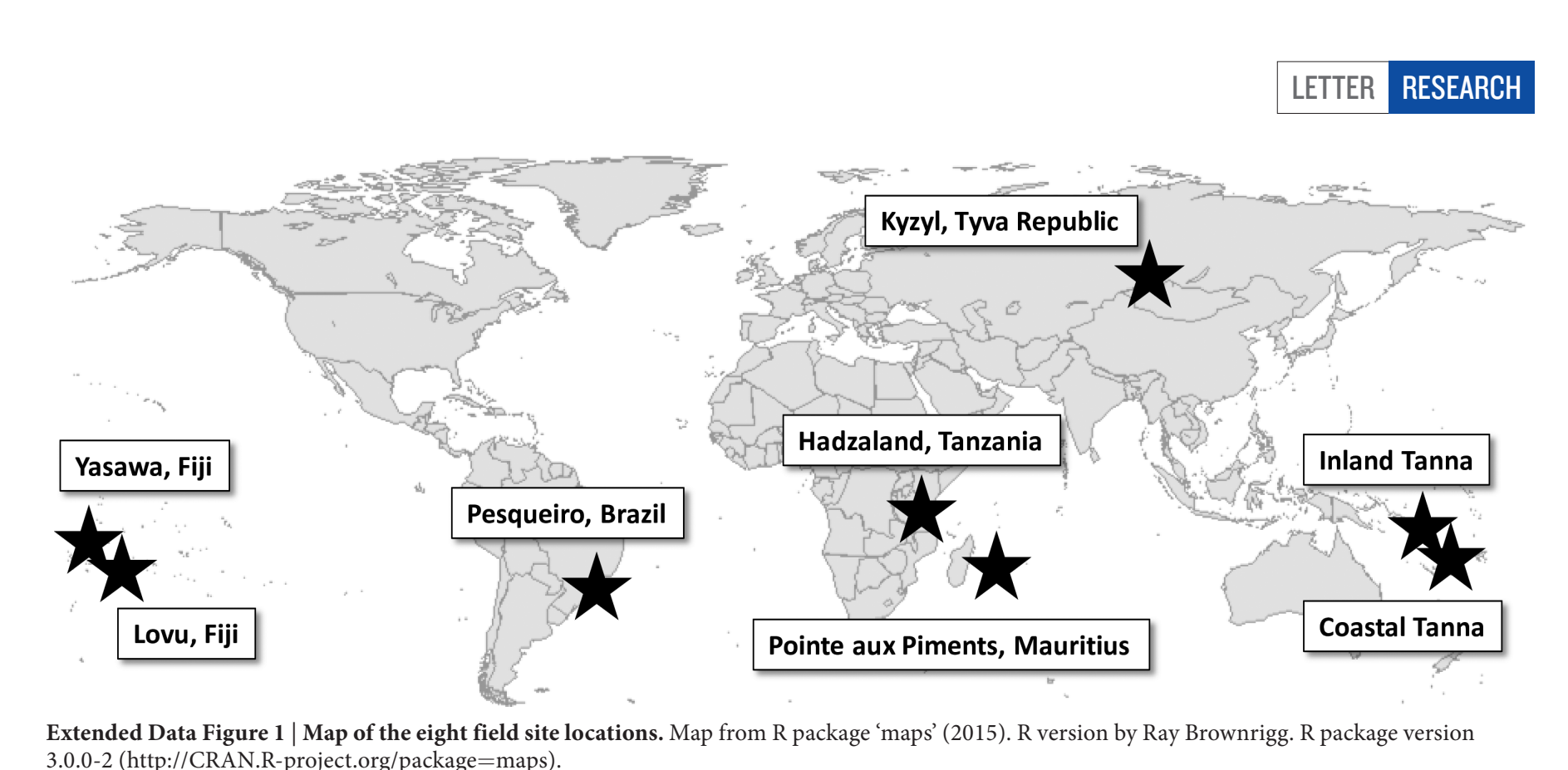



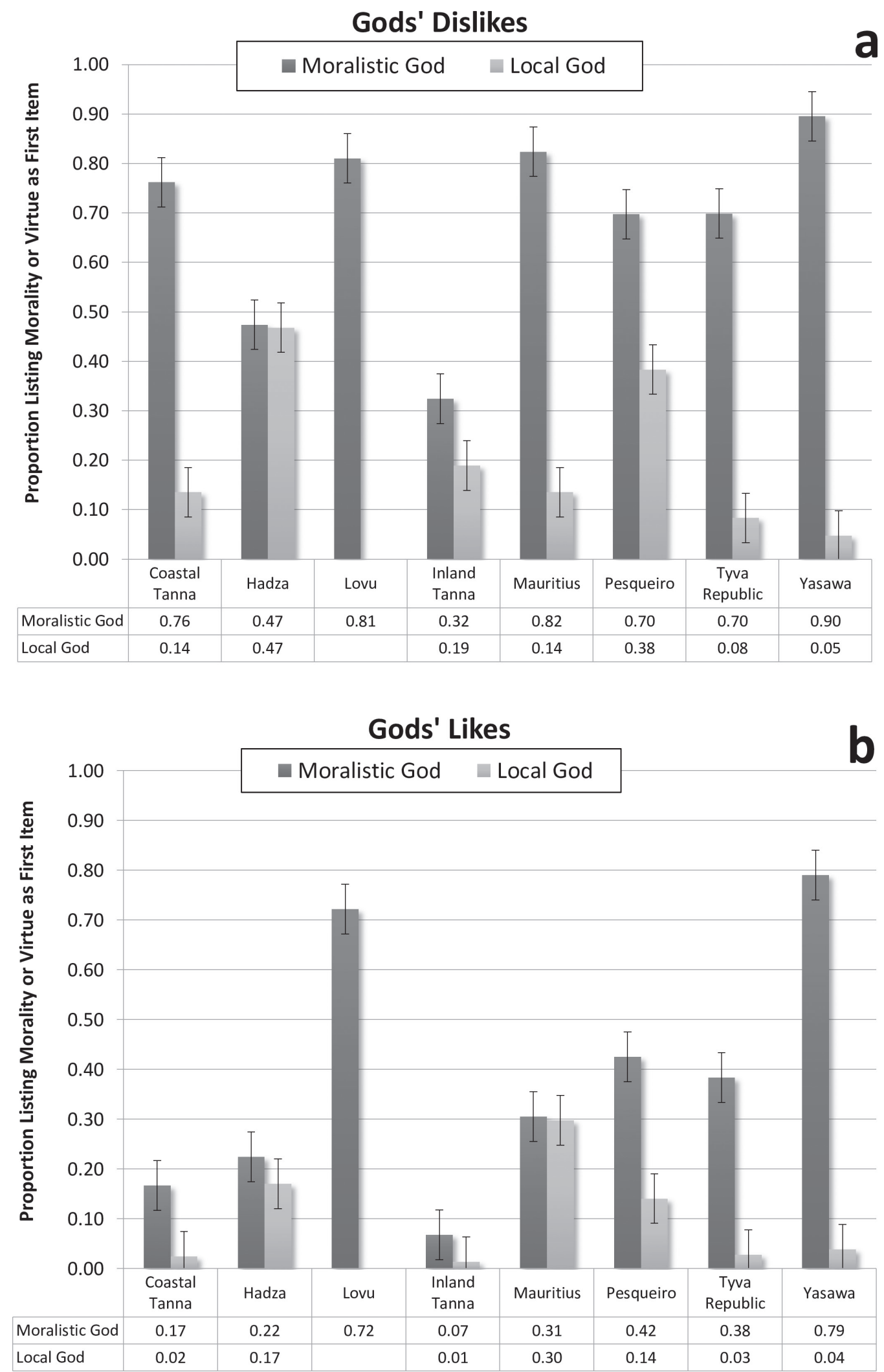

Extended Data Figure 2 Proportion of sample listing moral and virtue items for moralistic and local gods' dislikes and likes by site. a, b, We asked participants to freely list up to five things that moralistic and local gods dislike and like. These free-list items were subsequently coded by two independent coders using 12 categories (see Supplementary Information section S4.1.1 for the methods). Items listed first are the most salient items in participants' models of gods' concerns. Error bars have a total breadth of $10 \%$. Note that Indo-Fijians (Lovu) did not answer questions about local gods. 
Knowledge Scale

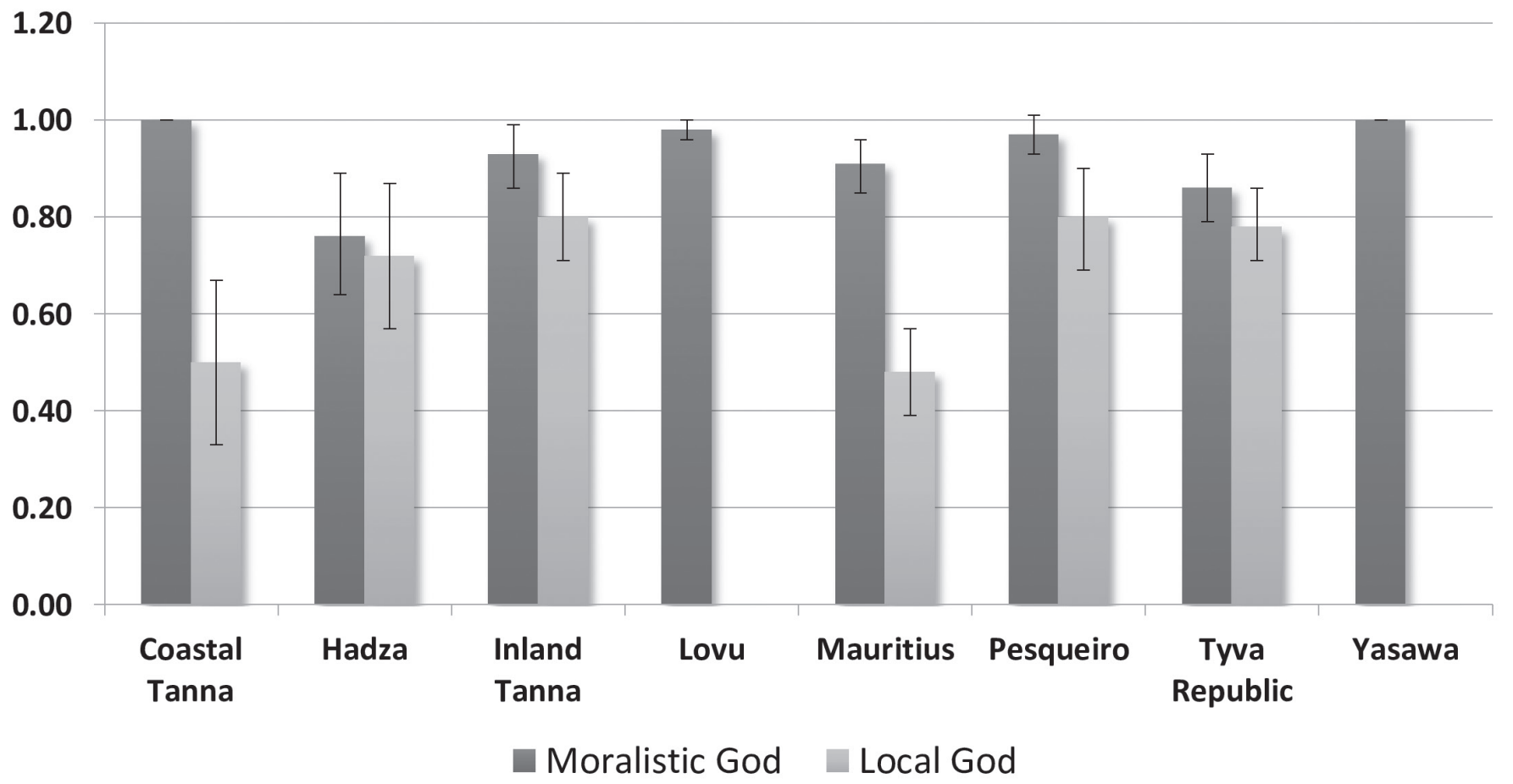

Punishment Scale

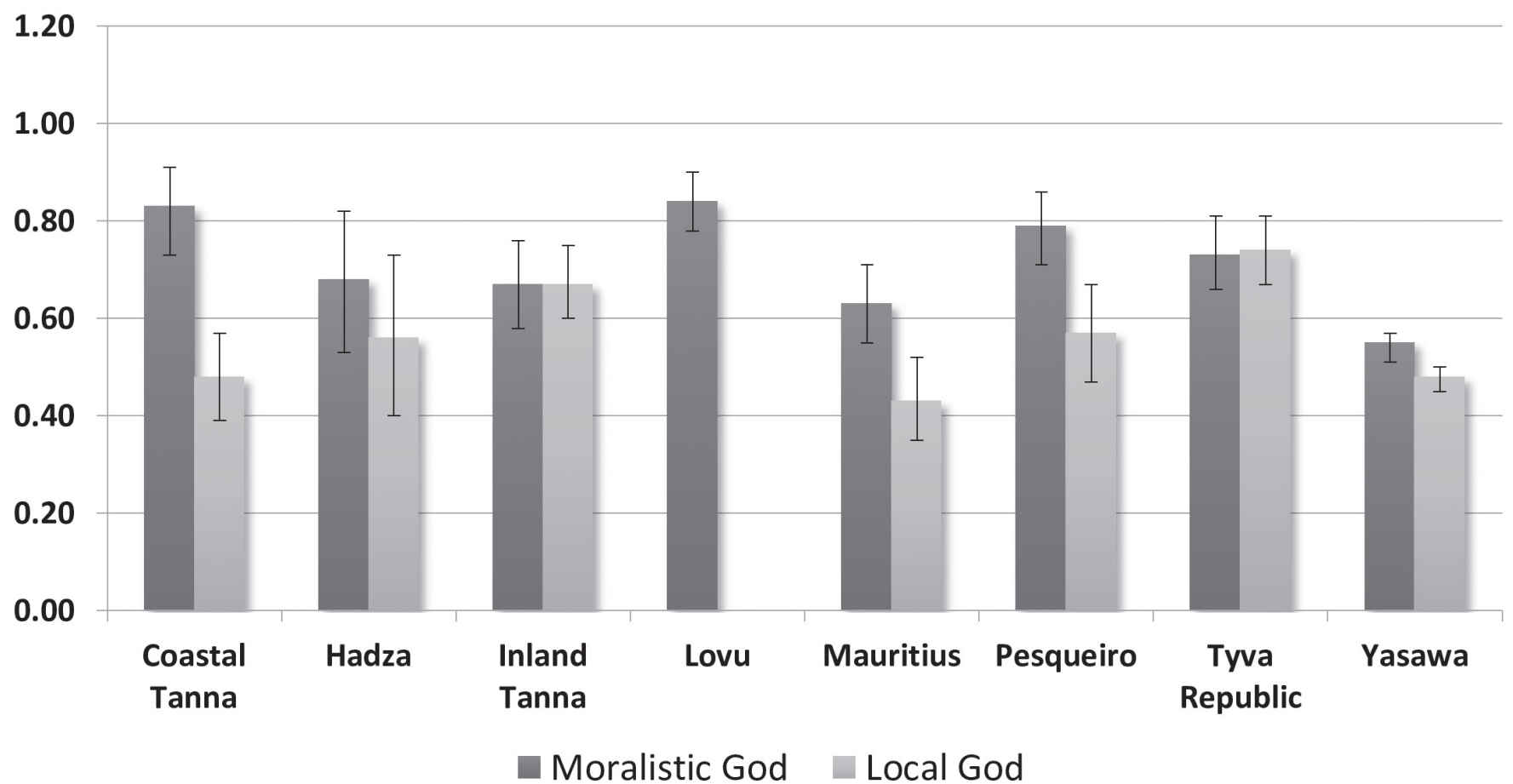

Extended Data Figure 3 Mean moralistic and local gods' knowledge and punishment scales by site. a, b, Error bars represent $95 \%$ confidence intervals of the mean. Lovu (Indo-Fijians) did not answer questions about local gods, and Yasawans' (native Fijians) attributions of ancestor spirits' knowledge had a mean and standard deviation of zero. Note that local gods often punish for non-moralistic reasons. See Supplementary Information sections S4.1 and S4.2 for methods and analyses. 


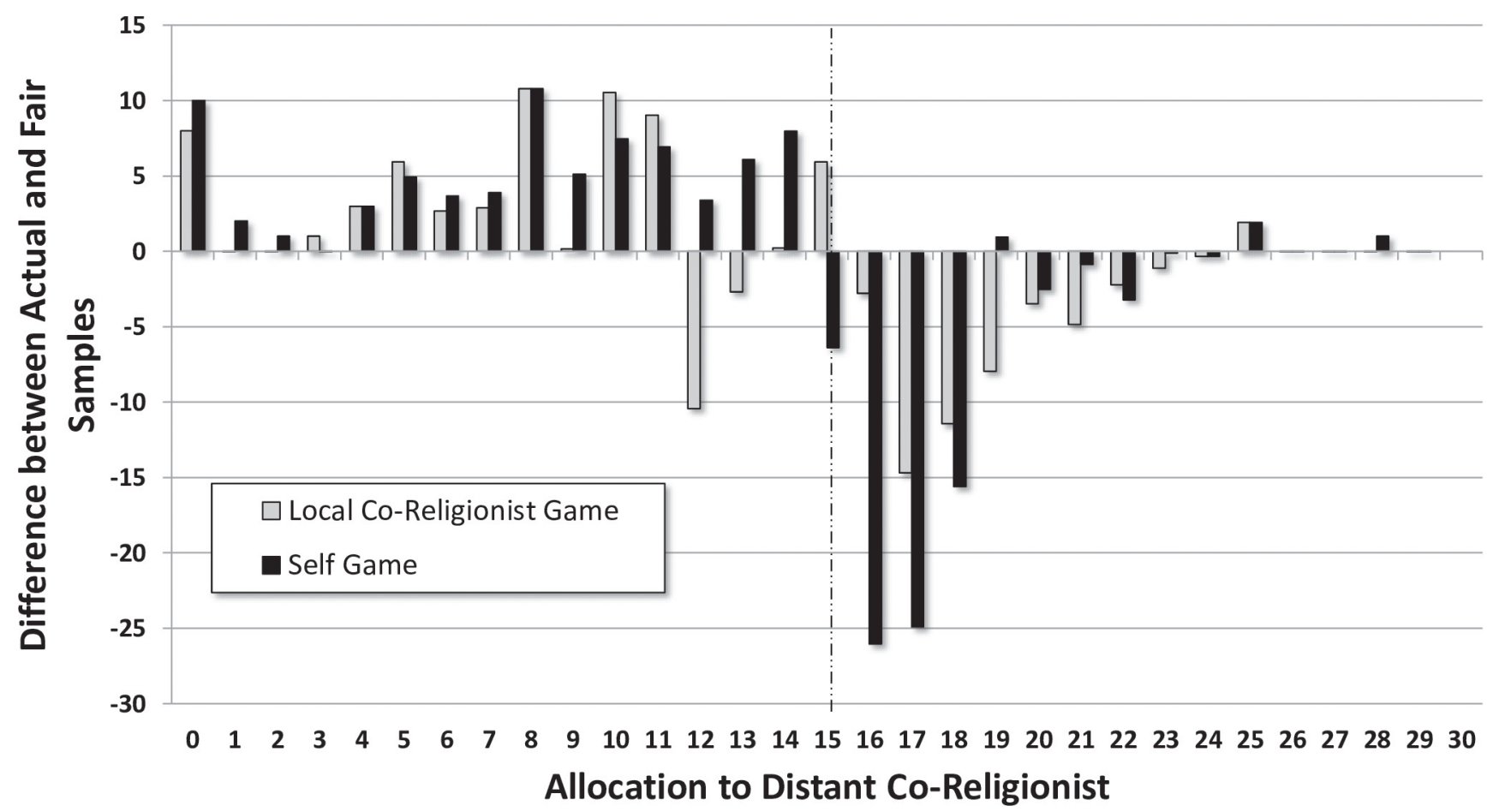

Extended Data Figure 4 | Plot of differences between size of actual allocations and allocations from binomially distributed sample of the same size. The halfway mark of 15 indicates the predicted mean of all cups. Bars above zero on the $y$ axis indicate higher frequencies of

allocations than predicted, and those lower indicate fewer individuals than predicted. Note the cluster of extremely lower-than-predicted values immediately after the cut-off point of 15 . 


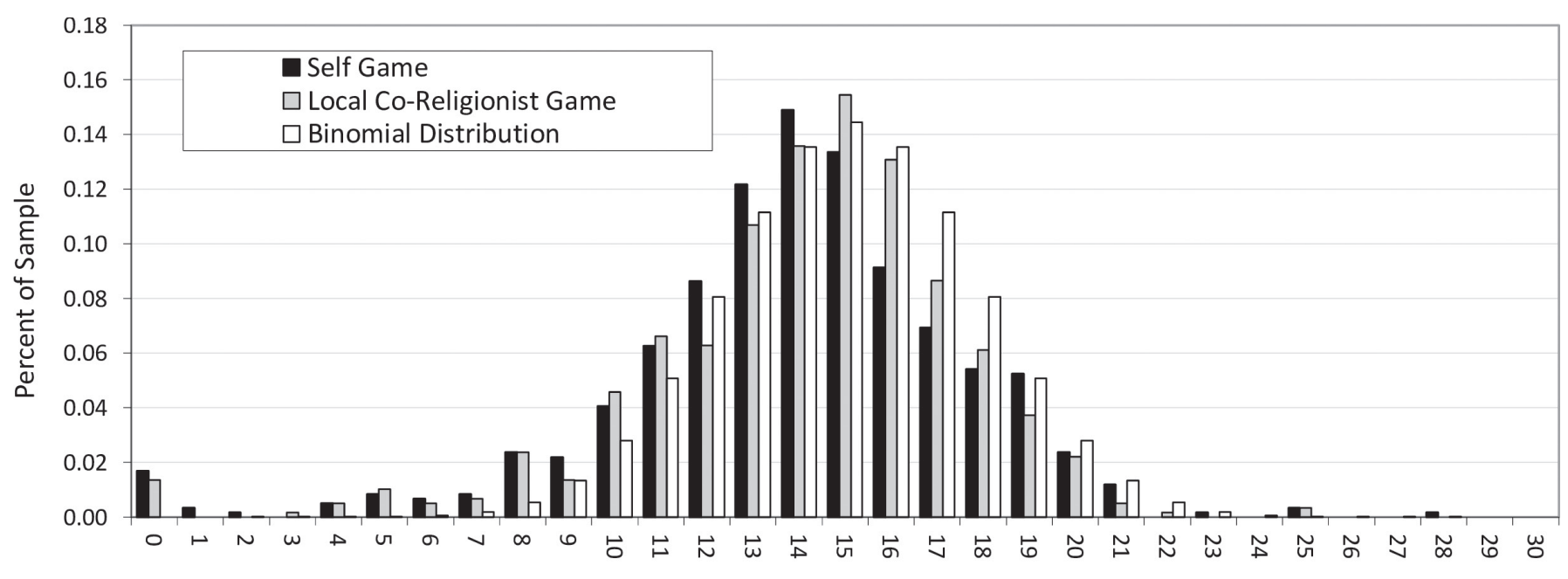

Number of Coins in DISTANT Cup

Extended Data Figure 5 | Per cent of sample by allocation amount to distant cup in local co-religionist (grey) and self games (black) as compared to binomial distribution (white). For both games, allocations

lean towards the left of a theoretically ideal binomial distribution suggesting that overall, participants biased allocations towards themselves $(n=591)$ and local co-religionists $(n=589)$ at the expense of geographically distant co-religionists. 


\section{RESEARCH LETTER}

Extended Data Table 1 | Models accounting for allocations to anonymous distant co-religionists with punishment-knowledge aggregate scales

\begin{tabular}{|c|c|c|c|c|c|c|}
\hline & $\begin{array}{c}1 \\
\begin{array}{c}\text { Local Co-Religionist } \\
\text { Game }\end{array}\end{array}$ & $\begin{array}{c}2 \\
\begin{array}{c}\text { Local Co-Religionist } \\
\text { Game }\end{array}\end{array}$ & $\begin{array}{c}3 \\
\text { Local Co-Religionist } \\
\text { Game }\end{array}$ & $\begin{array}{c}4 \\
\text { Self } \\
\text { Game }\end{array}$ & $\begin{array}{c}5 \\
\text { Self } \\
\text { Game }\end{array}$ & $\begin{array}{c}6 \\
\text { Self } \\
\text { Game }\end{array}$ \\
\hline Punishment-Knowledge (MG) & $1.20[1.04,1.37]^{*}$ & $1.27[1.08,1.50]^{* *}$ & $1.47[1.18,1.83]^{* * *}$ & $1.23[1.07,1.41]^{* *}$ & $1.40[1.18,1.65]^{* * *}$ & $1.51[1.21,1.88]^{* * *}$ \\
\hline Punishment-Knowledge (LG) & -- & $0.95[0.83,1.09]$ & $0.90[0.76,1.07]$ & -- & $1.00[0.88,1.14]$ & $1.04[0.88,1.23]$ \\
\hline Reward (MG) & -- & -- & $1.03[0.86,1.24]$ & -- & -- & $1.10[0.92,1.33]$ \\
\hline Reward (LG) & -- & -- & $0.92[0.79,1.08]$ & -- & -- & $0.93[0.79,1.09]$ \\
\hline Moral Index (MG) & -- & -- & $0.98[0.93,1.03]$ & -- & -- & $1.00[0.95,1.05]$ \\
\hline Moral Index (LG) & -- & -- & $1.03[0.98,1.08]$ & -- & -- & $0.98[0.93,1.03]$ \\
\hline Age (Centered) & $1.00[1.00,1.00]$ & $1.00[1.00,1.01]^{*}$ & $1.01[1.00,1.01]^{* *}$ & $1.00[1.00,1.01]^{*}$ & $1.01[1.00,1.01]^{* * *}$ & $1.01[1.00,1.01]^{* * *}$ \\
\hline Sex ( 0 = Female) & $1.06[0.99,1.14]^{\dagger}$ & $1.05[0.97,1.13]$ & $1.09[1.00,1.19]^{\dagger}$ & $1.03[0.96,1.10]$ & $1.07[0.99,1.15]^{\dagger}$ & $1.06[0.97,1.15]$ \\
\hline Years of Formal Education & $0.99[0.98,1.00]$ & $0.99[0.98,1.01]$ & $1.00[0.98,1.01]$ & $1.00[0.99,1.01]$ & $1.00[0.99,1.02]$ & $1.01[0.99,1.02]$ \\
\hline Material Insecurity & $1.01[0.92,1.11]$ & $1.08[0.97,1.20]$ & $1.09[0.96,1.23] \ddagger$ & $0.96[0.88,1.06]$ & $1.03[0.92,1.15]$ & $1.01[0.89,1.14]$ \\
\hline \# of Children & $0.99[0.97,1.01]$ & $0.97[0.95,0.99]^{* *}$ & $0.97[0.94,0.99]^{*}$ & $0.98[0.96,1.00]^{*}$ & $0.96[0.94,0.98]^{* * *}$ & $0.96[0.93,0.99]^{* *}$ \\
\hline DISTANT Religious Similarity & -- & -- & $1.01[0.961 .05]$ & -- & -- & $1.03[0.98,1.08]$ \\
\hline LOCAL Emotional Closeness & -- & -- & $0.98[0.94,1.03]$ & -- & -- & $1.00[0.95,1.04]$ \\
\hline DISTANT Emotional Closeness & -- & -- & $0.97[0.94,1.01]$ & -- & -- & $1.00[0.97,1.04]$ \\
\hline Police Evaluation & -- & -- & $1.03[0.98,1.09]$ & -- & -- & $1.03[0.98,1.09]$ \\
\hline Honesty Mentioned ( $0=\mathrm{No})$ & -- & -- & $0.92[0.76,1.11]$ & -- & -- & $1.19[0.99,1.44]^{\dagger}$ \\
\hline Treatment $(0=$ Control $)$ & $1.00[0.93,1.08]$ & $1.04[0.96,1.14]$ & $1.05[0.95,1.15]$ & $0.97[0.90,1.05]$ & $0.96[0.89,1.05]$ & $0.95[0.87,1.04]$ \\
\hline Game Order (0 = Self First) & $1.05[0.99,1.12] \ddagger$ & $1.08[1.01,1.16]^{*}$ & $1.12[1.03,1.22]^{* *}$ & $1.03[0.96,1.09]$ & $1.06[0.98,1.14] \ddagger$ & $1.11[1.02,1.20]^{*}$ \\
\hline Coastal Tanna & $0.98[0.83,1.16]$ & $1.06[0.86,1.30]$ & $1.08[0.86,1.34]$ & $0.87[0.73,1.02]^{\dagger}$ & $0.89[0.73,1.10]$ & $0.89[0.71,1.11]$ \\
\hline Hadza & $0.59[0.48,0.73]^{* * *}$ & $0.70[0.55,0.89]^{* *}$ & -- & $0.63[0.51,0.78]^{* * *}$ & $0.76[0.59,0.97]^{*}$ & -- \\
\hline Inland Tanna & $0.92[0.75,1.14]$ & $0.98[0.77,1.24]$ & $1.02[0.77,1.35]$ & $0.80[0.65,0.99]^{*}$ & $0.89[0.70,1.12]$ & $0.89[0.67,1.18]$ \\
\hline Lovu & $0.96[0.83,1.11]$ & -- & -- & $0.91[0.79,1.06]$ & -- & -- \\
\hline Mauritius & $0.90[0.78,1.04] \ddagger$ & $0.88[0.76,1.03] \ddagger$ & $0.91[0.75,1.10]$ & $0.77[0.66,0.88]^{* * *}$ & $0.78[0.67,0.91]^{* *}$ & $0.78[0.65,0.94]^{*}$ \\
\hline Pesqueiro & $0.91[0.78,1.06]$ & $0.91[0.77,1.08]$ & $0.89[0.72,1.10]$ & $0.90[0.77,1.04]$ & $0.84[0.71,0.99]^{*}$ & $0.94[0.77,1.16]$ \\
\hline Yasawa & $0.79[0.69,0.91]^{* *}$ & $0.77[0.66,0.90]^{* *}$ & $0.80[0.60,1.06] \ddagger$ & $0.62[0.54,0.72]^{* * *}$ & $0.63[0.54,0.74]^{* * *}$ & $0.64[0.48,0.86]^{* *}$ \\
\hline Constant & $0.88[0.70,1.12]$ & $0.86[0.66,1.13]$ & $0.85[0.60,1.22]$ & $0.98[0.78,1.24]$ & $0.81[0.61,1.06] \ddagger$ & $0.68[0.47,0.97]^{*}$ \\
\hline AIC & 2846.5 & 2224.2 & 1770.3 & 2990.4 & 2351.1 & 1920.7 \\
\hline Pseudo- $R^{2}$ & 0.19 & 0.18 & 0.19 & 0.23 & 0.26 & 0.31 \\
\hline $\mathbf{N}$ & 519 & $408^{a}$ & $323^{b}$ & 520 & $408^{a}$ & $323^{b}$ \\
\hline
\end{tabular}

Log odds ratios (and 95\% Cls) for variables predicting allocations to the distant co-religionist.

aLovu not included.

bHadza and Lovu not included.

All models are binomial logistic regressions, backward selected for site inclusion. Models include field sites as fixed effects. Moralistic god variables are denoted as 'MG' and local god variables are denoted as 'LG'. Pseudo $R^{2}$ s are Nagelkerke's $R^{2}$. *** $P \leq 0.001$, *** $P \leq 0.01, * P \leq 0.05,+P \leq 0.10, \ddagger P \leq 0.15$. See Supplementary Information section $S 2.3$ for variable definitions, Supplementary Information section S5 for discussion of analyses and Supplementary Table S9 for punishment-knowledge aggregate models with extreme values removed. 